\title{
Estratégia de Investimentos Baseada em Acidentes Aéreos: Há Retornos Anormais?
}

\begin{abstract}
Resumo
O presente trabalho buscou investigar se uma estratégia de investimentos baseada em acidentes aéreos geraria retornos anormais. Foi feito um estudo de eventos, considerando-se todos os acidentes aéreos ocorridos no período de 1998 a 2009 e os dados das companhias aéreas e dos fabricantes das respectivas aeronaves que possuíam ações negociadas nas bolsas de valores, quando da ocorrência do evento. Os testes realizados se basearam no modelo de Campbel, Lo e Mackinlay (1997), para definição de retornos anormais, por meio de uma regressão linear entre o retorno das ações dessas empresas e o retorno do portfólio de mercado utilizado como benchmark. Assim, foi possível projetar os retornos futuros esperados para as ações das companhias aéreas e fabricantes e compará-los aos resultados efetivamente obtidos na ocorrência do evento. $\mathrm{O}$ resultado obtido sugere que uma estratégica de investimentos baseada em acidentes aéreos seria viável e que retornos anormais poderiam ser obtidos no período imediatamente posterior um acidente aéreo.
\end{abstract}

Palavras-Chave: Acidentes Aéreos, Estudo de Eventos, Estratégia de Investimentos, Retorno Anormal e Retorno normal.

\section{Marcos Rosa Costa}

Mestre em Ciências Contábeis (Fucape). Contato: Av. Fernando Ferrari, 1358, Boa Vista, Vitória, ES, CEP 29075-505. E-mail: marcosrosa@uol.com.br

\section{Fernando Caio Galdi} Doutor em Controladoria e Contabilidade (USP), Professor da Fucape Business School. Contato: Av. Fernando Ferrari, 1358, Boa Vista, Vitória, ES, CEP 29075-505 E-mail: fernando.galdi@fucape.br

\section{Silvania Neris Nossa}

Doutoranda em Ciências Contábeis e Administração (Fucape). Contato: Av. Fernando Ferrari, 1358, Boa Vista, Vitória, ES, CEP 29075-505

E-mail: silvanianossa@uol.com.br 


\section{Introdução}

Acidentes aéreos são eventos incomuns, mas que mexem com os sentimentos das pessoas e tem grande repercussão social. A literatura de finanças comportamentais relata que determinadas situações podem gerar má percepção da realidade e, portanto, precificações inadequadas. Esse fenômeno é chamado de sentimento de mercado (market sentiment) e é tratado por Baker e Wurgler (2007). Exemplos de sentimento de mercado são o mau humor e a ansiosidade. Pessoas com o humor afetado e ansiosas podem ser mais pessimistas com relação aos retornos futuros e tender a assumir menos riscos (Kaplanski \& Levi, 2010).

O presente trabalho investiga se o mercado reage de forma exageradamente pessimista à informação de um desastre aéreo de maneira que um investidor possa se aproveitar da queda no preço das ações das empresas envolvidas em acidentes (fabricante e companhia aérea) e montar uma estratégia de investimento que resultará em retornos acima dos da média do mercado. O estudo deste tema é relevante, pois ajuda a entender como os investidores reagem a uma notícia notadamente ruim e quão eficiente o mercado é para ajustar os preços das ações negociadas em Bolsas de Valores.

Kaplanski e Levi (2010) encontraram evidências de que há perdas de mais de $\$ 60$ bilhões no valor de mercado de empresas no caso de acidentes aéreos, enquanto a perda real estimada não passa de \$1bilhão. Contudo, os autores mostram que há uma reversão de preço em aproximadamente dois dias. Em nosso estudo, investigamos os impactos nos preços das ações das companhias aéreas e também dos fabricantes de aeronaves e as possibilidades de obtenção de retornos anormais com base em uma estratégia que considera a informação de desastre aéreo como gatilho para a aquisição de ações.

Os acidentes aéreos considerados nesta pesquisa ocorreram entre 1998 e 2009. No entanto desses dados foram analisados, unicamente, os acidentes daquelas companhias que possuíam ações negociadas nas bolsas de valores à época do acidente, em pregões de seu país de origem ou nas bolsas de valores de outros países. Como não existe uma definição única para "acidente aéreo", neste trabalho, foram considerados somente aqueles acidentes nos quais existiram, no mínimo, 10 (dez) vítimas fatais.

Acidentes aéreos são eventos inesperados e cuja ocorrência provoca impacto no valor das ações das empresas envolvidas, conforme mencionam McWilliamns e Siegel (1997) e Kaplanski e Levy (2010). Levando-se em consideração o acidente aéreo como um evento que influencia o preço das ações das companhias envolvidas nos momentos próximos à sua ocorrência, e também que essa influência seria mensurável, foi elaborado o seguinte problema de pesquisa: é possível obter retornos anormais com uma estratégia de investimento baseada em acidentes aéreos?

Para responder à questão de pesquisa, foram consideradas as hipóteses: $h_{0}$ : a hipótese nula de que uma estratégia de investimentos baseada em acidentes aéreos não proporciona retornos anormais. $\mathrm{E} \mathrm{h}_{1}$ : a hipótese alternativa foi a de que uma estratégia de investimentos baseada em acidentes aéreos proporciona retornos anormais.

A hipótese testada considera que os investimentos em ações de companhias aéreas, quando da ocorrência de acidentes aéreos, geram retornos anormais. Caso ocorressem retornos anormais, os investimentos, com base nesse tipo de evento, teriam retornos superiores aos obtidos pelos portfólios, nos mercados específicos de cada país, em que a empresa envolvida possuísse ações negociadas.

O objetivo da presente pesquisa é investigar se uma estratégia de investimentos baseada em acidentes aéreos proporcionaria, ou não, retornos anormais. Para isso, foi estudada a relação entre acidentes aéreos e investimentos em ações das companhias envolvidas nesses acidentes, baseando-se no conceito de overreaction para os preços de ações de empresas envolvidas. No trabalho desenvolvido por Barberis, Shleifer e Vishny (1998, p.7), eles definiram que "[...] a reação excessiva ocorre quando a média dos retornos seguintes, não a um, mas a uma série de anúncios de boas notícias, for menor do que aqueles retornos médios seguintes, a uma série de anúncios de más notícias".

Para atingir esse objetivo, foi investigado se, por meio da utilização da metodologia de estudo de eventos, com análise do retorno das ações das companhias aéreas e fabricantes de aeronaves, era possível confirmar a existência de retornos anormais, após a data do acidente, com base no preço das ações no 
mercado. Para tal, foram consideradas tanto as ações das companhias aéreas, quanto às dos fabricantes de aeronaves envolvidos no acidente.

A pesquisa se justifica por ter buscado esclarecer a viabilidade de uma estratégia de investimentos, baseada em eventos inesperados e não antecipados pelo mercado, como no caso de um acidente aéreo.

Ao ser considerada a definição de Mackinlay (1997) de que, usando dados do mercado financeiro, um estudo de evento permite medir o impacto de um evento específico sobre o valor da empresa no mercado, a relevância deste trabalho se sustenta por utilizar a metodologia de estudo de eventos para dimensionar o impacto de um evento como um acidente aéreo no preço das ações das companhias envolvidas. O resultado obtido por meio do estudo de eventos, neste trabalho, permite avaliar se acidentes aéreos podem ser analisados como algo além de um desastre humano.

\section{Fundamentação Teórica}

A análise de retorno sobre investimentos em ações por longos períodos implica a utilização de teorias e de modelos previamente testados. Assim sendo, por se tratar de uma pesquisa baseada em retornos anormais, serão utilizados os conceitos definidos por Campbell, Lo e Mackinlay (1997), em seu trabalho The econometrics of financial markets e, também, no trabalho de Mackinlay (1997), Event Studies in Economics and Finance, no qual foram considerados os modelos para medir retornos anormais, como modelos estatísticos e modelos econômicos. Neste estudo, com base nas premissas definidas pelos autores supramencionados, foi adotada a definição de modelo estatístico de retornos ajustados ao risco e ao mercado.

McWilliams e Siegel (1997), em trabalho desenvolvido, refizeram e compararam com o trabalho anteriormente desenvolvido por Wright, Ferris, Hiller e Kroll (1995), que utilizavam a metodologia de estudo de eventos. McWilliams e Siegel identificaram que, durante a janela do evento selecionada pelos pesquisadores daqueles trabalhos em análise, vários eventos que ocorreram impactaram seu resultado e foram deixados de fora da análise. Eles também identificaram que, ao serem incorporadas novas variáveis, como o tamanho da janela, os retornos anormais naqueles trabalhos eram insignificantes e não suportavam as teses de Wright et al. (1995).

McWilliamns e Siegel (1997) ressaltam que o método de estudo de eventos tem se tornado popular devido ao fato de as medidas baseadas no lucro contábil terem sido bastante criticadas como um indicador não muito robusto da verdadeira performance das companhias. Daí teria surgido a necessidade de modelos que refletissem mais rapidamente os acontecimentos nos mercados e que tivessem como base a evolução do preço das ações.

De acordo com Prabhala (1997), um estudo de eventos teria duas propostas fundamentais, sejam elas: 1 - testar se há um "efeito informação" no preço da ação e 2 - identificar fatores que expliquem mudanças no valor de mercado da companhia na ocorrência de um dado evento. Prabhala (1997) acredita que, embora a metodologia de estudo de eventos venha sendo amplamente utilizada em trabalhos empíricos, pouco é compreendido sobre seu poder e consistência, diante de um conjunto de expectativas racionais.

Os mercados eficientes de capital são também explicados por Ross, Westerfield e Jaffe (2007, p. 277) como:

[...] aqueles nos quais os preços correntes de mercado refletem a informação disponível. Isso significa que os preços correntes de mercado refletem o valor presente dos títulos e que não há maneira alguma de obter lucros extraordinários com o uso das informações disponíveis.

Segundo McWilliams e Siegel (1997, p. 650), um estudo de evento deve fornecer uma medida verdadeira do impacto financeiro de um evento e, para tal, um conjunto de premissas necessita ser respeitado, quais sejam: 1- Os mercados são eficientes; 2- Os eventos não foram antecipadamente previstos; e 3 - Não ocorreu nenhum evento que possa influenciar o preço da ação e confundir a análise durante a janela do evento. 
Em um trabalho posterior desenvolvido por Barberis e Thaler (2002, p.2), eles justificaram que as finanças comportamentais são uma nova forma de analisar o mercado financeiro e que essas finanças tiveram sua importância aumentada, em parte, graças às dificuldades encaradas pelos paradigmas tradicionais, pois alguns fenômenos financeiros são mais bem compreendidos quando se usam modelos nos quais os agentes não são completamente racionais. Nesse sentido, Gigerenzer (2004), Flannagan e Sivak (2004) estudaram o efeito dos acidentes aéreos no comportamento dos clientes de empresas aéreas e chegaram à conclusão de que o ambiente negativo provocado pela queda dos aviões em 11 de setembro teve efeito no aumento significativo do tráfico de veículos nas estradas e teve efeito na queda no número de pessoas viajando de avião nos EUA.

Daniel, Hirshleifer e Subrahmanyam (1998) desenvolveram um trabalho empírico sob a ótica do sentimento do investidor. Consideraram a psicologia para suportar sua ideia de under e overreaction, muito embora os fundamentos de seu trabalho fossem overconfidence e self-atribuition, o que o diferenciou do trabalho posterior desenvolvido por Barberis et al. (1998). No entanto esses três autores acreditam que os dois trabalhos tiveram a mesma intenção, que foi a de gerar evidência empírica no campo das finanças comportamentais.

Daniel et al. (1998) definiram um investidor overconfidente como aquele que superestima a precisão do sinal da informação privada por ele recebida, mas, não, das informações recebidas publicamente por todos. Baker e Wurgler (2007) estudaram dois cenários: no primeiro cenário, o investidor recebe uma notícia negativa e isso reflete forte e negativamente no preço das ações. Mas, quando o investidor recebe uma notícia positiva, a variação no humor do investidor é positiva e o peso no retorno das ações dessas mesmas empresas não é tão forte e positivo, quando comparado ao impacto do primeiro cenário. Os resultados de Baker e Wurgler (2007) são coerentes com os achados de Barberis et al. (1998), que sugerem que, na underreaction, o retorno médio das ações das companhias, no período posterior a um anúncio de boas notícias, é maior que o retorno médio dessas ações, em período posterior ao anúncio de más notícias; o que equivale dizer que o mercado financeiro é underreacts às boas notícias e que esse erro seria corrigido no período seguinte ao anúncio do evento, quando ocorre, então, um retorno maior. Nesse mesmo trabalho, Barberis et al. (1998) consideraram como "boas notícias" a publicação de lucros maiores do que os esperados pelo mercado, muito embora eles também acreditem que há evidências de underreaction em outros tipos de notícias.

A utilização do termo overreaction, na concepção de Barberis et al. (1998, p.7), seria quando os retornos médios - considerando-se uma série estatisticamente representativa, após a divulgação de boas notícias -, forem menores do que os retornos de outra série correspondente, após a divulgação de más notícias. Para eles a explicação seria que:

A ideia aqui é simplesmente que, após uma série de anúncios de boas notícias, o investidor torna-se excessivamente otimista de que as notícias futuras também serão boas e, então, ele reage em excesso, enviando desnecessariamente, o preço das ações para altos níveis. Anúncios posteriores são prováveis de contradizer seu otimismo, levando a baixos retornos. [TRADUÇÃO NOSSA].

Kaplanski e Levy (2010) estudaram o efeito das notícias recebidas pelos investidores e encontraram evidências de que os sentimentos negativos levam ao mau humor e ansiedade, que levam às decisões de investimento em ações. Kaplanski e Levy (2010) pesquisaram o efeito dos desastres de aviões no preço das ações e encontraram evidências empíricas de que o preço sofre efeitos negativos e significativos, se comparado ao preço médio do mercado. Eles encontraram perdas de mais de 60 bilhões por desastre de avião e ainda perceberam evidências empíricas de aumento da volatilidade implícita após a queda de aviões.

Com relação ao cálculo dos retornos anormais, Martinez (2004) sugere que, de forma sintética, esses retornos anormais seriam a diferença entre o retorno normal da ação, caso o evento (acidente) não tivesse ocorrido, e o retorno efetivamente observado dessa mesma ação, na ocorrência do evento. Martinez (2004) também sugere e descreve algumas técnicas consideradas adequadas e que podem ser adotadas para o cálculo desses retornos normais e anormais. 
A técnica de estudo de eventos para identificar retornos anormais foi utilizada no Brasil por Nakayasu (2006), que, ao analisar "o impacto do anúncio e da adesão das ações aos níveis diferenciados de governança corporativa no Brasil", concluiu que o evento "data do anúncio" da migração para um dos níveis diferenciados de governança corporativa da Bovespa causa reação positiva no mercado. O evento "data de adesão", por sua vez, não revelou nenhum impacto na reação do mercado.

\section{Metodologia}

Os dados relativos aos acidentes aéreos foram coletados, considerando-se a base de dados disponível no site www.planecrashinfo.com, entre os anos de 1998 e 2009.

O número de acidentes aéreos e de vítimas fatais dessas ocorrências, por companhia aérea, considerado no presente trabalho, encontra-se sintetizado na Tabela 1.

Tabela 1

Número de vítimas fatais e acidentes por companhia aérea

\begin{tabular}{lcc}
\hline \multicolumn{1}{c}{ Cia Aérea } & Número de vítimas fatais & Número de acidentes \\
\hline American AirLines & 427 & 4 \\
\hline Gol Linhas Aéreas & 154 & 1 \\
\hline TAM & 187 & 1 \\
\hline Total Geral & 768 & 6 \\
\hline
\end{tabular}

Fonte: site www.planecrashinfo.com

O número de acidentes aéreos e de vítimas fatais, por fabricante de aeronave, considerados neste tratado, encontra-se resumido na Tabela 2.

Tabela 2

Número de vítimas fatais e acidentes por fabricante

\begin{tabular}{lcc}
\hline \multicolumn{1}{c}{ Fabricante } & Número de $\cdot$ vítimas fatais & Número de acidentes \\
\hline Airbus & 1211 & 7 \\
\hline Bae Systems & 38 & 3 \\
\hline Boeing & 4551 & 53 \\
\hline Embraer & 114 & 5 \\
\hline Lockheed & 239 & 6 \\
\hline Textron & 110 & 10 \\
\hline Total Geral & 6263 & 84 \\
\hline
\end{tabular}

Fonte: site www.planecrashinfo.com

Ressalta-se que o total de acidentes da Tabela 1 e 2 diferem, pois nem todas as aeronaves acidentadas são de companhias aéreas listadas em Bolsa.

Ao todo, considerando-se o critério de que a companhia aérea e o fabricante devam ter ações negociadas nas bolsas de valores, chegou-se à quantidade de 84 (oitenta e quatro) acidentes aéreos, sendo que esta seria a quantidade total de acidentes aéreos com no mínimo 10 (dez) vítimas fatais, no período de 1998 a 2009, em todo o mundo.

Os dados relacionados às cotações das ações foram coletados, utilizando-se o software Economática e foram levadas em conta as informações já ajustadas aos proventos distribuídos. Só foi possível obter informações financeiras de algumas empresas, localizadas em outros países, no site http://www.finance.yahoo.com. 


\subsection{Definição das etapas de um estudo de eventos}

Apesar de não existir uma estrutura rígida para condução de um estudo de evento, utilizando-se como base os modelos propostos por Mackinlay (1997) e Campbell et al. (1997), a presente pesquisa trata de uma estrutura com sete etapas fundamentais: (1) definição do evento, (2) critérios de seleção da amostra, (3) mensuração dos retornos normais e anormais, (4) procedimentos de estimação, (5) procedimentos de teste, (6) resultados empíricos e (7) interpretações e conclusões.

Como primeiro passo para um estudo de eventos, deve-se definir o evento a ser analisado. Em seguida, convém definir o período em que o retorno da ação será analisado, a chamada “janela do evento". Embora o critério de seleção de tamanho seja uma decisão do pesquisador nessa seleção, é importante que a janela do evento contenha os dias considerados relevantes para investigar a existência de anormalidade nos retornos.

Identificados os eventos a serem analisados, o passo seguinte consiste em selecionar a amostra de empresas que serão testadas. Pelo fato de o presente estudo visar ao teste da existência de retornos anormais nas ações das empresas aéreas e fabricantes de aeronaves após um acidente aéreo, somente aquelas empresas sujeitas a uma alteração no valor de suas ações por conta desse evento foram consideradas.

A medida do impacto do evento depende de uma forma adequada de se medir o retorno anormal. A dimensão dos retornos anormais consiste em comparar o retorno normal da ação com o retorno obtido pelo modelo de estimação da ação. O retorno normal da ação é definido como retorno que a ação obteria, caso não tivesse ocorrido o evento. Para essa análise, de acordo com o modelo de Campbell et al. (1997), seria conveniente que a data do evento não fosse considerada nos cálculos dos retornos esperados, para não comprometer o resultado obtido pelo modelo de estimação. Segundo o modelo de Mackinlay (1997, p.15), para uma empresa $i$ na data $t$, o retorno anormal seria:

$$
A R_{i t}=R_{i t}-E\left(R_{i t} / X_{t}\right)
$$

Em que:

$A R_{i p} R_{i t} e E\left(R_{i t} / X_{t}\right)$ são o retorno anormal, o retorno de fato e o retorno normal para a ação i no tempo $t$, respectivamente.

$X_{t}$ é a condicionante do modelo de retorno normal, determinado pelo retorno ajustado por um modelo de estimação anterior ao evento.

De acordo com Mackinlay (1997), existem duas formas comuns de se definirem retornos normais, quais sejam: (1) modelo de retorno constante ajustado à média, em que $X_{t}$ seria uma constante; e (2) modelo de mercado, em que $X_{t}$ é o retorno de mercado. Considerando-se que, no modelo de mercado, este assume uma relação linear estável entre o retorno do mercado e o retorno da ação, esse foi o modelo adotado na presente pesquisa.

Para o cálculo do retorno do investimento em ação, foi utilizado o regime de capitalização contínua, no qual é utilizado o (ln) logaritmo natural para o cálculo do retorno dos títulos e do portfólio utilizado como benchmarking. O modelo de capitalização contínua, conforme equação 1, é o modelo sugerido por Campbell et al. (1997).

A expressão do modelo de capitalização é:

$$
R_{i t}=\frac{\ln \left(\ln P_{t)}\right)}{\ln \left(\ln P_{t-1}\right)}
$$

Em que:

$R_{i t}=$ é o retorno da ação $i$ na data $t$;

$\ln P_{t}=$ é o logaritmo natural do preço da ação $i$ no período $t$

$\ln P_{t-1}=$ é o logaritmo natural do preço da ação $i$ no período $t-1$. 
Ao ser definido o modelo de cálculo do retorno normal, o próximo passo a ser dado é definir a "janela de estimação" que irá resultar nos parâmetros do modelo de estimação. Mackinlay (1997) sugere que a "janela do evento" não deve ser incluída na "janela de estimação", para não influenciar no cálculo dos parâmetros que servirão de base para o modelo de estimação. Após serem definidos os parâmetros dos retornos normais do modelo, segundo Nakayasu (2008), o próximo passo será elaborar os procedimentos de cálculo dos retornos anormais das ações e a técnica de agregação desses retornos. Nessa fase, é quando se efetua também o teste de hipótese, em que a hipótese nula $\left(\mathrm{H}_{0}\right)$ e a hipótese alternativa $\left(\mathrm{H}_{1}\right)$ são identificadas.

A apresentação dos resultados, de acordo com Mackinlay (1997), segue a formulação desenho econométrico. A análise do resultado, identificando-se os possíveis outliers, cabe ao pesquisador, sobretudo, quando a amostra não for suficientemente grande.

Nesse último passo, chega-se à hipótese testada, rejeitando-se, ou não, a existência de retornos anormais após a ocorrência do evento acidente aéreo. Nesse ponto, é possível inferir se o evento em análise possui efeito sobre o preço das ações das companhias aéreas e dos fabricantes de aeronaves.

\subsection{Cálculo utilizando retornos normais}

No cálculo da diferença entre os retornos normais dos títulos das companhias envolvidas e o retorno dos índices de mercado utilizado como benchmarking, foram utilizados teste F ANOVA para análise de variância e teste $\mathrm{F}$ para testar igualdade de variâncias entre os retornos diários normais e os retornos diários normais acumulados, tanto para as empresas de transporte de passageiros quanto para os fabricantes das aeronaves envolvidas.

Após o cálculo do retorno normal da ação de cada companhia envolvida e do portfólio a ser considerado para comparação, conforme equação 1, procedeu-se a um dos cálculos para se buscar identificar a presença de retorno anormal, com base no modelo sugerido por Martinez (2004), que é o modelo estatístico dos retornos ajustados ao mercado. Tais retornos são obtidos pela diferença entre o retorno da ação e o retorno do portfólio de mercado, no qual foram utilizados os retornos normais diários e acumulados, obtidos entre os dias de negociação +2 e +360 pós-evento e comparados ao retorno dos portfólios de mercado nesse mesmo período. A fórmula dos retornos ajustados ao mercado é a seguinte:

$$
A_{., i, t}=R_{i . t}-R_{m . t}
$$

Em que:

$A_{i . t}=$ é o retorno anormal calculado no período t;

$R_{m . t}=$ é o retorno do portfólio do mercado no período t;

$R_{i, t}=$ é o retorno normal da ação no período t.

Finalizando a etapa de análise dos retornos normais, foi aplicado o teste T para duas amostras, presumindo variâncias diferentes, em que foram comparados os retornos normais diários e acumulados para as ações das empresas aéreas e fabricantes, com os retornos dos portfólios.

\subsection{Cálculo utilizando o modelo de estimação}

Com base na metodologia para condução de um estudo de eventos definida por Mackinlay (1997, p.20), foram, então, definidos os retornos normais esperados (ER) e os retornos anormais. O retorno normal $\left(\mathrm{R}_{\mathrm{i} . \mathrm{t}}\right)$ foi calculado como o retorno esperado $\mathrm{E}(\mathrm{R})$, caso o evento não tivesse ocorrido, definido com base no intercepto $(\hat{\alpha} i)$ e no coeficiente angular $(\widehat{\beta} i)$, resultados da regressão linear entre o retorno da ação das empresas envolvidas (x) e o portfólio do mercado (y) utilizado como referência. 
O estudo de eventos no presente trabalho foi definido, considerando-se: (1) o período de 60 (preços de fechamento da ação) antes do acidente, período este identificado como "janela de estimação"; (2) o período de 59 (preços de fechamento da ação) após a ocorrência do acidente, que foi identificado como "janela de comparação"; e (3) no intervalo entre a "janela de estimação" e a "janela de comparação", foi isolado o período de 2 (preços de fechamento da ação), identificado como a "janela do evento", para evitar que o período de ocorrência do evento interferisse no resultado das variáveis do modelo de estimação (Campbell et al.,1997).

Para estimar o retorno futuro das ações, foi utilizada uma regressão linear simples entre o retorno das ações das companhias envolvidas e o retorno do portfólio de mercado. Para que fossem definidos os parâmetros da equação ( $\widehat{\propto} i$ e $\widehat{\beta} i$ ) da constante e do coeficiente da regressão linear, a variável independente foi o retorno do portfólio do mercado $\left(\mathrm{R}_{\mathrm{m} . t}\right)$ e a variável dependente foi o retorno efetivo da ação da companhia.

Após definidos a constante e o coeficiente da regressão entre o retorno do preço da ação e o retorno do portfólio do mercado, foi identificada, com base nos pressupostos de Campbell et al. (1997), a equação do Modelo de Estimação, que é o retorno esperado (normal) da ação:

$$
E\left(R_{i, t}\right)=(\hat{\alpha} i+\hat{\beta} i \times R m . t)
$$

Em que:

$E\left(R_{i, t}\right)=$ é o retorno esperado (normal) da ação $i$ na data $t$

$\hat{\alpha} i=$ é a constante estimada da regressão linear

$\widehat{\beta} i=$ é o coeficiente angular estimado da regressão

$R m . t=$ é o retorno da carteira de Mercado na data $t$

Com base nos mesmos pressupostos da equação 3, o cálculo dos retornos anormais foi feito a partir de cada evento, dentro de cada dia (preço no fechamento) da janela de comparação. A fórmula para definição dos retornos anormais ficou assim definida:

$$
A R_{i, t}=R_{i, t}-(\hat{\alpha} i+\widehat{\beta} i \times R m \cdot t)
$$

\footnotetext{
Em que:

$A R_{i, t}=$ é o retorno anormal da ação $i$ na data $t$

$R_{i, t}=$ é o retorno observado da ação $i$ na data $t$

$\hat{\alpha} i=$ é a constante estimada da regressão linear

$\widehat{\beta} i=$ é o coeficiente angular estimado da regressão

$R m . t=$ é o retorno da carteira de Mercado na data $\mathrm{t}$
}

Após apurados os retornos anormais (AR) para cada evento, conforme equação 4, alinhados com os pressupostos do modelo de Campbell et al. (1997), foram verificados os retornos anormais (AR) e os retornos anormais médios $(\overline{\mathrm{AR}})$, com base na soma dos retornos anormais diários de cada evento, dividido pelo total de eventos. E também foi apurado o retorno anormal acumulado médio ( $\overline{\mathrm{CAR}})$, obtido pela acumulação da média diária dos retornos anormais médios $(\overline{\mathrm{AR}})$ para todos os eventos analisados.

Após serem apurados o retorno anormal médio $(\overline{\mathrm{AR}})$ e o retorno anormal acumulado médio $(\overline{\mathrm{CAR}})$, foram efetuados novos testes $\mathrm{T}$ para duas amostras, presumindo variâncias diferentes. Porém, nesse estágio, os testes foram baseados dos dias 15, 30, 45 e 60 da janela de comparação. Na ocorrência de retornos anormais positivos, o teste $\mathrm{T}$ permitiu identificar em qual período da janela de comparação seria viável a elaboração de uma estratégia de investimentos baseada em acidentes aéreos. 


\subsubsection{Diagnóstico do modelo de regressão}

Após calculados os parâmetros para projeção dos retornos esperados para a ação em cada evento, obtidos com base na regressão linear entre o retorno de cada ação e o retorno do portfólio, foi aplicado o teste de linearidade da função de regressão para verificar a existência, ou não, de relação linear entre o retorno das ações das empresas analisadas e o portfólio.

Os testes de linearidade, tanto para os eventos das companhias aéreas quanto para os fabricantes, foram feitos considerando-se o retorno das ações e o retorno dos portfólios, num mesmo período de tempo. Os níveis de significância, utilizando-se a estatística $t$ de student para o coeficiente $(\beta)$ do modelo testado, deveriam apresentar valores com significância estatística mínima de 10\%, sendo os eventos que não obedeceram à significância mínima de $10 \%$ excluídos da análise. Desse modo, a análise final foi aplicada a 57 (cinquenta e sete) eventos dos fabricantes e 5 (cinco) eventos das companhias aéreas, que foram aqueles eventos que apresentaram relação linear significante.

\section{Resultados dos Testes}

Os resultados apresentados a seguir tiveram o objetivo de buscar identificar se os retornos obtidos por um investimento, feito no período imediatamente posterior a um acidente aéreo, em ações de companhias aéreas e fabricantes dos respectivos aviões envolvidos, são diferenciados em relação ao portfólio de mercado utilizado como benchmarking.

\subsection{Testes de diferença de média}

O resultado dos testes $\mathrm{T}$ e $\mathrm{F}$ apresentados a seguir tiveram com base o retorno normal das ações e revelou dados sobre o comportamento dos retornos diários das ações dos fabricantes de avião e das companhias aéreas, comparado-as aos portfólios de mercado considerados para cada evento.

Ao se estratificar a análise, o resultado do teste estatístico F para igualdade de variâncias entre os retornos diários médios das ações dos fabricantes e os retornos diários médios dos portfólios de mercado revelou um $\mathrm{F}=3,65$, significante a 0,01 . O resultado sugere que não há indícios de que a hipótese nula de que a variância da média dos retornos diários das ações e a variância da média dos retornos diários dos portfólios analisados sejam iguais.

O resultado do Teste $\mathrm{F}$ de duas amostras para variância entre os retornos diários acumulados médios das ações dos fabricantes e o portfólio de mercado confirmou os resultados citados acima. Os resultados obtidos revelaram um $\mathrm{F}=2,69$, significante a 0,01 , não acatando a hipótese nula $\mathrm{H}_{0}$ de que as variâncias são iguais e sustentando o fato de que se trata de amostras com variâncias distintas.

O teste F para duas variâncias, considerando a média geral de todos os retornos diários das ações das companhias aéreas de transporte de passageiro, com um $\mathrm{F}=7,94$ e significante a 0,01 , sugeriu que existe diferença entre as variâncias dos retornos diários das ações das empresas de transporte de passageiros (companhias aéreas) e a variância dos retornos dos portfólios utilizados como benchmarking.

A aplicação do teste F para duas variâncias, considerando a média geral dos retornos diários acumulados das empresas de transporte de passageiros e dos índices de mercados, revelou um F =67,39 significante a 0,01 , sugerindo que existe diferença entre as variâncias dos retornos, o que indica a possibilidade de existência de retornos anormais.

Os testes para verificação de diferença de variância utilizados, com base na definição de Stephan et al. (2005, p. 357), revelaram que existe diferença entre a variância do retorno das ações das companhias aéreas e dos fabricantes versus o retorno do portfólio. 
O teste $\mathrm{T}$ para duas amostras, presumindo variâncias diferentes, buscou identificar a diferença entre a média dos retornos acumulados das ações dos fabricantes e das companhias aéreas e a média dos retornos acumulados dos índices utilizados como benchmarking. Quando considerados os retornos acumulados nos dias de negociação 30, 60, 90, 120, 150, 180, 210, 240, 270, 300, 330 e 360, após a ocorrência do evento (acidente aéreo), o teste revelou que a hipótese nula $\mathrm{H}_{0}$ não deve ser acatada. Com um $\mathrm{t}=-7,4872$ para os fabricantes e um $t=-3,86$ para companhias aéreas, sugere-se que o retorno das ações dos fabricantes dos aviões e das companhias aéreas, quando na ocorrência de acidentes aéreos com suas aeronaves, é menor do que o retorno dos portfólios de mercado no mesmo período.

Os resultados apresentados com base nos retornos normais, embora sugira indícios, não possibilitaram identificar a existência de retornos anormais. Novos testes foram aplicados, e os resultados seguem na sequência.

\subsection{Resultados do modelo de regressão}

Para que fossem utilizados como estimadores dos retornos esperados, os resultados com base no modelo de regressão, se utilizado o período definido na janela de estimação, deveriam apresentar significância mínima de $10 \%$, sendo que os eventos que não apresentaram tal significância foram eliminados do presente estudo.

Os resultados foram divididos em 4 tabelas para melhor visualização. Na Tabela 3, estão sintetizados os resultados obtidos no período de 2 a 15 dias com negociação, após a ocorrência do evento (acidente), bem como os retornos anormais médios (AR Médio) e os retornos anormais acumulados (CAR Médio) obtidos para as ações das companhias aéreas e dos fabricantes de aeronaves e os respectivos valores do teste $\mathrm{Z}$ para significância estatística.

Tabela 3

Resultados do estudo de evento para os fabricantes e companhias aéreas entre os dias de negociação 2 até 15 , após 0 acidente

\begin{tabular}{ccccc}
\hline \multirow{2}{*}{$\begin{array}{c}\text { Dias em Relação } \\
\text { à data do evento }\end{array}$} & AR Médio & CAR Médio & AR Médio & CAR Médio \\
\cline { 2 - 5 } & $0,185 \%^{* *}$ & $0,185 \%$ & $1,147 \%{ }^{*}$ & $1,147 \%$ \\
\hline 2 & $-0,103 \%$ & $0,082 \%$ & $1,009 \% *$ & $2,168 \%$ \\
\hline 4 & $-0,070 \%$ & $0,012 \%$ & $-0,374 \%$ & $1,785 \%$ \\
\hline 5 & $0,083 \%$ & $0,095 \%$ & $-1,431 \%$ & $0,328 \%$ \\
\hline 6 & $0,214 \%^{*}$ & $0,309 \%$ & $-0,068 \%$ & $0,260 \%$ \\
\hline 7 & $0,454 \%^{*}$ & $0,764 \%$ & $-0,123 \%$ & $0,136 \%$ \\
\hline 8 & $0,371 \% *$ & $1,138 \%$ & $0,842 \% *$ & $0,979 \%$ \\
\hline 9 & $0,027 \%$ & $1,165 \%$ & $-0,123 \%$ & $0,854 \%$ \\
\hline 10 & $0,135 \%$ & $1,302 \%$ & $1,497 \% *$ & $2,364 \%$ \\
\hline 11 & $0,235 \% *$ & $1,540 \%$ & $-0,087 \%$ & $2,276 \%$ \\
\hline 12 & $0,110 \%$ & $1,652 \%$ & $-0,061 \%$ & $2,214 \%$ \\
\hline 13 & $0,513 \% *$ & $2,173 \%$ & $1,100 \% *$ & $3,338 \%$ \\
\hline 14 & $0,003 \%$ & $2,176 \%$ & $1,120 \% *$ & $4,495 \%$ \\
\hline 15 & $0,689 \%^{*}$ & $2,880 \%$ & $0,172 \%$ & $4,674 \%$ \\
\hline
\end{tabular}

Nota. * com um nível de significância de 1\%.

** com um nível de significância de $5 \%$.

*** com um nível de significância de $10 \%$. 
A análise do período entre os dias 2 e 15 com negociação, após a data do evento, permitiu identificar a presença de retornos anormais para os fabricantes nos dias 2, 6, 7, 8, 11, 13 e 15 e, para as companhias aéreas nos dias 2, 3, 8, 10, 13 e 14 .

$\mathrm{Na}$ Tabela 4, estão sintetizados os retornos anormais médios e os retornos anormais acumulados médios obtidos, bem como os respectivos valores do teste $\mathrm{Z}$ para significância estatística, no período que vai do dia 16 a 30 com negociação, após a data do acidente aéreo.

Tabela 4

Resultados do estudo de evento para os fabricantes e companhias aéreas entre os dias de negociação 16 até 30 , após o acidente

\begin{tabular}{ccccc}
\hline \multirow{2}{*}{$\begin{array}{c}\text { Dias em Relação } \\
\text { à data do evento }\end{array}$} & AR Médio & CAR Médio & AR Médio & CAR Médio \\
\cline { 2 - 5 } & $-0,082 \%$ & $2,796 \%$ & $0,725 \%$ * & $5,433 \%$ \\
\hline 16 & $0,098 \%$ & $2,896 \%$ & $-1,277 \%$ & $4,086 \%$ \\
\hline 18 & $-0,264 \%$ & $2,625 \%$ & $0,595 \%$ ** & $4,706 \%$ \\
\hline 19 & $0,052 \%$ & $2,678 \%$ & $3,388 \%$ * & $8,253 \%$ * \\
\hline 20 & $-0,045 \%$ & $2,632 \%$ & $-2,369 \%$ & $5,689 \%$ \\
\hline 21 & $-0,414 \%$ & $2,207 \%$ & $0,544 \%$ ** & $6,263 \%$ \\
\hline 22 & $0,082 \%$ & $2,290 \%$ & $0,654 \%$ * & $6,958 \%$ \\
\hline 23 & $0,100 \%$ & $2,392 \%$ & $-0,833 \%$ & $6,067 \%$ \\
\hline 24 & $0,405 \% *$ & $2,807 \%$ & $-1,526 \%$ & $4,449 \%$ \\
\hline 25 & $-0,165 \%$ & $2,637 \%$ & $0,223 \%$ & $4,682 \%$ \\
\hline 26 & $-0,067 \%$ & $2,568 \%$ & $-0,170 \%$ & $4,504 \%$ \\
\hline 27 & $-0,065 \%$ & $2,501 \%$ & $-1,159 \%$ & $3,293 \%$ \\
\hline 28 & $0,238 \% *$ & $2,745 \%$ & $-0,357 \%$ & $2,924 \%$ \\
\hline 29 & $-0,113 \%$ & $2,629 \%$ & $-0,285 \%$ & $2,631 \%$ \\
\hline 30 & $1,063 \% *$ & $3,719 \% * * *$ & $0,486 \% * * *$ & $3,130 \%$ \\
\hline
\end{tabular}

Nota. * com um nível de significância de $1 \%$.

** com um nível de significância de $5 \%$.

*** com um nível de significância de $10 \%$.

Na Tabela 4, com relação aos fabricantes, nota-se que o maior retorno anormal médio (AR), com 1\% de significância, está no dia 30 de negociação após a ocorrência do evento e, nesse mesmo dia, o retorno anormal acumulado médio (CAR) foi significante a 10\%. Com relação às ações das companhias aéreas, o maior AR médio está no dia de negociação 19, com 3,38\% de retorno; e, nesse mesmo dia, o CAR foi significante a $1 \%$ e chegou a $8,25 \%$ no acumulado.

Os resultados obtidos para retornos anormais, até o dia de negociação 30, após a ocorrência do acidente aéreo, sugerem que uma estratégia de investimento que fosse elaborada, tendo como base o evento acidente aéreo, cuja intenção fosse resgatá-la em até 30 dias de negociação após evento, seria estatisticamente pouco provável a existência de retornos diferenciados em relação ao mercado. Estes indícios foram observados, uma vez que nesse período, CAR médio é pouco significante.

$\mathrm{Na}$ Tabela 5, estão sintetizados os retornos anormais médios e os retornos anormais acumulados obtidos, e os respectivos valores do teste $Z$ para significância estatística no período que vai do dia 31 a 45 com negociação, após a data do acidente aéreo. 
Tabela 5

Resultados do estudo de evento para os fabricantes e companhias aéreas entre os dias de negociação 31 até 45, após o acidente

\begin{tabular}{|c|c|c|c|c|}
\hline \multirow{2}{*}{$\begin{array}{l}\text { Dias em Relação } \\
\text { à data do evento }\end{array}$} & \multicolumn{2}{|c|}{ Fabricantes } & \multicolumn{2}{|c|}{ Cias. Aéreas } \\
\hline & AR Médio & CAR Médio & AR Médio & CAR Médio \\
\hline 31 & $-0,407 \%$ & $3,297 \%$ & $0,902 \%$ * & $4,060 \%$ \\
\hline 32 & $0,055 \%$ & $3,354 \%$ & $-1,554 \%$ & $2,443 \%$ \\
\hline 33 & $0,168 \%$ ** & $3,527 \%$ & $0,296 \%$ & $2,746 \%$ \\
\hline 34 & $-0,232 \%$ & $3,287 \%$ & $0,862 \%$ * & $3,632 \%$ \\
\hline 35 & $0,186 \%$ ** & $3,480 \%$ & $0,649 \%$ * & $4,305 \%$ \\
\hline 36 & $-0,035 \%$ & $3,443 \%$ & $0,197 \%$ & $4,511 \%$ \\
\hline 37 & $-0,097 \%$ & $3,343 \%$ & $-0,231 \%$ & $4,270 \%$ \\
\hline 38 & $0,189 \%$ ** & $3,538 \%$ & $-0,418 \%$ & $3,834 \%$ \\
\hline 39 & $0,100 \%$ & $3,641 \%$ & $0,508 \% * * *$ & $4,361 \%$ \\
\hline 40 & $0,338 \%$ * & $3,992 \%$ * & $-0,352 \%$ & $3,994 \%$ \\
\hline 41 & $0,379 \%$ * & $4,386 \%$ * & $-1,226 \%$ & $2,720 \%$ \\
\hline 42 & $0,204 \%$ * & $4,599 \%$ * & $2,049 \%$ * & $4,824 \%$ \\
\hline 43 & $0,013 \%$ & $4,613 \%$ * & $1,874 \%$ * & $6,789 \%$ \\
\hline 44 & $0,124 \%$ & $4,743 \%$ * & $1,806 \%$ * & $8,717 \%$ * \\
\hline 45 & $0,594 \%$ * & $5,365 \%$ * & $2,946 \%$ * & $11,920 \%$ * \\
\hline
\end{tabular}

Nota. * com um nível de significância de $1 \%$.

** com um nível de significância de $5 \%$.

*** com um nível de significância de $10 \%$.

A Tabela 5 mostra que, para as ações dos fabricantes, os retornos anormais médios (AR) continuaram acontecendo com significância estatística de $1 \%$ e 5\% e, a partir do dia de negociação 40, os retornos anormais acumulados médios (CAR) começaram a acontecer e apresentaram significância estatística de $1 \%$ entre os dias de negociação 40 e 45 , quando CAR chegou a 5,36\% para os fabricantes e a $11,92 \%$ para as companhias aéreas.

Até o dia de negociação 40, após a data de ocorrência do acidente, embora existissem retornos anormais médios significantes, no acumulado, não havia sido possível se verificar uma tendência. A partir daí, pode-se notar que a ocorrência persistente dos retornos anormais significantes estatisticamente a $1 \%, 5 \%$ e $10 \%$ mostrou um retorno anormal acumulado médio, com aparente tendência de crescimento.

Na Tabela 6, estão sintetizados os retornos anormais médios e os retornos anormais acumulados obtidos, além dos respectivos valores do teste $\mathrm{Z}$ para significância estatística, no período que vai do dia 46 a 60 com negociação, após a data do acidente aéreo. 
Tabela 6

Resultados do estudo de evento para os fabricantes e companhias aéreas entre os dias de negociação 46 até 60 , após 0 acidente

\begin{tabular}{|c|c|c|c|c|}
\hline \multirow{2}{*}{$\begin{array}{l}\text { Dias em Relação } \\
\text { à data do evento }\end{array}$} & \multicolumn{2}{|c|}{ Fabricantes } & \multicolumn{2}{|c|}{ Cias. Aéreas } \\
\hline & AR Médio & CAR Médio & AR Médio & CAR Médio \\
\hline 46 & $-0,170 \%$ & $5,186 \%$ * & $-0,923 \%$ & $10,887 \%$ * \\
\hline 47 & $-0,062 \%$ & $5,121 \%$ * & $0,542 \%$ ** & $11,488 \%$ * \\
\hline 48 & $0,129 \%$ & $5,257 \%$ * & $-0,050 \%$ & $11,433 \%$ * \\
\hline 49 & $-0,427 \%$ & $4,807 \%$ * & $0,566 \% * \star$ & $12,063 \%$ * \\
\hline 50 & $-0,060 \%$ & $4,744 \%$ * & $1,028 \%$ * & $13,215 \%$ * \\
\hline 51 & $0,492 \%$ * & $5,260 \%$ * & $0,842 \%$ * & $14,168 \%$ * \\
\hline 52 & $0,342 \%$ * & $5,620 \%$ * & $0,242 \%$ & $14,444 \%$ * \\
\hline 53 & $0,182 \%$ ** & $5,811 \%$ * & $1,147 \%$ * & $15,757 \%$ * \\
\hline 54 & $0,225 \%$ * & $6,050 \%$ * & $-1,127 \%$ & $14,453 \%$ * \\
\hline 55 & $-0,131 \%$ & $5,910 \%$ * & $-1,564 \%$ & $12,663 \%$ * \\
\hline 56 & $0,435 \%$ * & $6,370 \%$ * & $-0,072 \%$ & $12,582 \%$ * \\
\hline 57 & $-0,280 \%$ & $6,073 \%$ * & $1,497 \%$ * & $14,268 \%$ * \\
\hline 58 & $0,055 \%$ & $6,131 \%$ * & $-0,247 \%$ & $13,986 \%$ * \\
\hline 59 & $0,177 \%$ ** & $6,318 \%$ * & $1,853 \%$ * & $16,099 \%$ * \\
\hline 60 & $0,341 \%$ * & $6,681 \%$ * & $1,882 \%$ * & $18,283 \%$ * \\
\hline
\end{tabular}

Nota. * com um nível de significância de $1 \%$.

** com um nível de significância de $5 \%$.

*** com um nível de significância de 10\%.

Os resultados apresentados na Tabela 6, para o período entre os dias de negociação 46 e 60, mostram uma maior frequência de retornos anormais médios (AR) significantes estatisticamente a $1 \%$ e $5 \%$, tanto para as ações dos fabricantes quanto para os papéis das companhias aéreas. Quanto aos retornos anormais acumulados médios (CAR), em todos os dias do período que vai dos dias de negociação 46 a 60, eles se mostraram significantes estatisticamente a $1 \%$ para ações dos fabricantes e das companhias aéreas. No dia de negociação 60, o CAR médio acumulado chegou a 6,68\% para ações dos fabricantes e a 18,28\% para as ações das companhias aéreas.

\section{Considerações Finais}

O presente estudo procurou mostrar se uma estratégia de investimentos baseada em acidentes aéreos geraria, ou não, retornos anormais. Foi considerada uma metodologia apropriada, um estudo de eventos, baseado no modelo desenvolvido por Campbell et al. (1997), sendo esse modelo o mais testado e referenciado, segundo as revisões literárias feitas nessa pesquisa. Para tanto, os conceitos de finanças comportamentais como "over" e "underreaction" foram também trabalhados, já que se trata de acidentes aéreos, eventos inesperados e não antecipados pelo mercado de capitais.

A hipótese testada era de que uma estratégia de investimento baseada em acidentes aéreos geraria retornos anormais e, para tanto, foram analisados todos os acidentes das companhias aéreas e dos fabricantes de aviões que possuíam ações negociadas nas bolsas de valores, quando da ocorrência do acidente.

Para que fosse criado um modelo que pudesse definir os retornos futuros das ações, foram considerados como portfólios a referência de mercado de cada país onde os acidentes ocorreram, o índice 
Dow Jones da Bolsa valores de Nova York, o índice Ibovespa da Bolsa de Valores de São Paulo e o índice CAC40, da Bolsa de Valores de Paris. Outros índices não foram utilizados por não existirem na amostra empresas de outros países e, também, pelo fato de os índices selecionados serem os mais referenciados na literatura revisada.

O teste F para diferença de variância, aplicado aos retornos normais, demonstrou que existia diferença entre as variâncias dos retornos normais das ações das companhias aéreas e dos fabricantes, ante os portfólios de mercado. O teste F ANOVA revelou que existia pelo menos uma amostra na qual a variância da média era diferente. Esses resultados sugeriram a necessidade de testes específicos para esta pesquisa.

Os resultados encontrados nesta pesquisa foram obtidos por meio do teste T, para diferença de média, presumindo variâncias diferentes. Foram analisadas as médias dos retornos normais, diárias e acumuladas, de todos os eventos, nos dias de negociação $30,60,90,120,150,180,210,240,270,300,330 \mathrm{e}$ 360 após cada acidente; permitiram identificar que as médias dos retornos normais das ações das companhias aéreas e dos fabricantes eram menores do que a média dos retornos normais dos portfólios. Como se tratava de testes embasados na diferença entre os retornos normais das ações das companhias versus os portfólios, esses resultados foram insuficientes para indicar ou refutar a presença de retornos anormais.

Embora os testes citados até então não tenham sido conclusivos, eles serviram para diagnosticar a necessidade de se buscar um método estatístico que melhor refletisse a realidade dos dados e que trouxesse um menor viés na sua interpretação. Os novos testes deveriam ser robustos quanto à premissa de que os dados eram normalmente distribuídos. Os novos testes aplicados tiveram o intuito de fornecer embasamento que possibilitasse inferir se, estatisticamente, uma estratégia de investimentos baseadas em acidentes aéreos geraria, ou não, retornos anormais. A partir daí, foi utilizado o modelo de estimação baseado no modelo de mercado, de acordo com Mackinlay (1997) e Campbell et al. (1997). Para esses autores, o modelo de mercado eliminaria grande parte dos erros cometidos em outros modelos que também são utilizados para o cálculo de retornos de ativos.

Os resultados obtidos com a aplicação do modelo de Campbell et al. (1997) revelaram a existência de retornos anormais tanto para as ações dos fabricantes de aeronaves quanto para as ações das companhias aéreas. No entanto os retornos anormais acumulados médios somente foram significantes a partir do dia de negociação 40, para as ações dos fabricantes e, do dia de negociação 45, para as ações das companhias aéreas; ambas as datas se referem aos dias que se seguiram à ocorrência dos eventos (acidentes).

Os testes $\mathrm{T}$ aplicados para duas amostras, presumindo variâncias diferentes, utilizados para comparação de médias dos retornos anormais diários (AR médio), para ações dos fabricantes de aeronaves e das companhias aéreas, apresentaram forte oscilação, revelando retornos anormais positivos e negativos nos dias de negociação 15, 30, 45 e 60. Os resultados obtidos indicaram que, no dia de negociação 60 pós-evento, que foi o último dia da análise, o CAR médio foi de 6,68\% para ações dos fabricantes e 18,28\% ações das companhias aéreas.

Os resultados apresentados revelaram que é possível que uma estratégia de investimentos baseada em acidentes aéreos obtenha retornos anormais. Assim, os retornos obtidos por uma aplicação que tenha sua estratégia elaborada com base nos fundamentos apresentados no presente trabalho seriam superiores àqueles obtidos por uma aplicação em outra carteira de ações que se baseasse nos índices de referência das bolsas de valores.

Por se tratar de cálculos relacionados ao comportamento dos títulos, devido à complexidade das variáveis envolvidas no mercado financeiro, cabe ressaltar que outros eventos podem ter ocorrido durante o período analisado, influenciado no cálculo dos retornos das ações e, consequentemente, no modelo de estimação dos retornos normais e anormais. Todavia, como os testes estatísticos seguiram as premissas de que os dados eram normalmente distribuídos, acredita-se que os resultados obtidos foram pouco influenciados por variáveis exógenas que não puderam ser controladas no modelo utilizado. 


\section{Referências}

Barberis, N., Shleifer, A. \& Vishny, R. A. (1998, setembro). Model of Investor Sentiment. Journal of Financial Economics, 49(3), 307-343.

Barberis, N.; Thaler, R. H. (2002). A Survey of Behavioral Finance. Recuperado em 12 julho, 2009 de http:// papers.ssrn.com/sol3/papers.cfm?abstract_id $=327880$.

Baker, M., \& Wurgler, J. (2006). Investor sentiment and the cross-section of stock returns. Journal of Finance, 61(4), 1645-1680. DOI: 10.1111/j.1540-6261.2006.00885.x

Baker, M., \& Wurgler, J. (2007). Investor sentiment in the stock market. Journal of Economic Perspectives, 21(2), 129-151.

Campbell, J. Y., LO, A. W., \& Mackinlay, A. C. (1997). The econometric of financial markets (611 p.) New Jersey: Princeton University Press.

Daniel, K., Hirshleifer, D., \& Subrahmanyam, A. (1998, dezembro). Investor Psychology and Security Market Under- and Overreactions. The Journal of Finance, 53(6), 1839-1885.

Flannagan, J., \& Sivak, M. (2004). Consequences for road traffic fatalities of the reduction in flying following September 11, 2001 Transportation Research: Part F, 7(4/5), 301-305.

Gigerenzer, G. (2004). Dread risk, September 11, and fatal traffic accidents. Psychological Science, 15(4), 286-287.

Kaplanski, G., \& Levy, H. (2010). Sentiment and Stock Prices: The case of aviation disasters. Jounal of Financial Economics, 95(2), 174-201.

Stephan, D., Levine, D. M. \& Krehbiel T. C. (2005). Estatística: Teoria e Aplicações Usando o Microsoft Excel em Português (3a ed., 819 p.). Rio de Janeiro: LTC.

Mackinlay, A. C. (1997, março). Event Studies in Economics e Finance. Journal of Economics Literature, 35(1), 13-39.

Martinez, A. L. (2004). Analisando os Analistas: estudo empírico das projeções de lucros e das recomendações dos analistas de mercado de capitais para as empresas brasileiras de capital aberto. Tese doutoral, Fundação Getúlio Vargas, São Paulo, SP, Brasil.

Mcwilliams, A., \& Siegel, D. (1997, junho). Event Studies in Management: Theorical and Empirical Issues. The Academy of Management Journal, 40(3), 626-657.

Nakayasu, G. N. (2006). O impacto do anúncio e da adesão das ações aos níveis diferenciados de governança corporativa no Brasil. Dissertação de Mestrado, Faculdade de Economia, Administração e Contabilidade da Universidade de São Paulo, São Paulo, SP, Brasil.

Prabhala, N. R. (1997, spring). Conditional Methods in Event Studies and Equilibrium Justification for Standard Event-Study Precedures. The Review of Financial Studies, 10(1), 1-38.

Ross, S. A., Westerfield, R. W., \& Jaffe, J. F. (2007). Administração Financeira: corporate finance. (2nda. ed., 777 p.) São Paulo: Atlas.

Wright, P., Ferris, S. P., Hiller, J. S., \& KROLL, M. (1995). Competitiveness Through Management of Diversity: Effects on Stock Price Valuation. Academy of Management Journal, 38(1), 272-287. doi: $10.2307 / 256736$. 